\title{
Early hemodynamics and clinical outcomes of isolated aortic valve replacement with stentless or transcatheter valve in intermediate-risk patients
}

\author{
Alberto Repossini, MD, ${ }^{\mathrm{a}}$ Lorenzo Di Bacco, MD, ${ }^{\mathrm{a}}$ Bruno Passaretti, MD, ${ }^{\mathrm{b}}$ Herko Grubitzsch, MD, \\ Christina Schäfer, MD, ${ }^{\mathrm{c}}$ Benjamin Claus, MD ${ }^{\mathrm{c}}$ Laura Giroletti, MD, ${ }^{\mathrm{a}}$ Thierry Folliguet, MD, ${ }^{\mathrm{d}}$ \\ Gianluigi Bisleri, MD, ${ }^{\mathrm{e}}$ Theodor Fischlein, MD, ${ }^{\mathrm{f}}$ Giuseppe Santarpino, MD,${ }^{\mathrm{f}}$ Roberto Di Bartolomeo, MD, ${ }^{\mathrm{g}}$ \\ François Laborde, $\mathrm{MD},{ }^{\mathrm{h}}$ and Claudio Muneretto, $\mathrm{MD}^{\mathrm{a}}$
}

\section{ABSTRACT}

Objective: Stentless aortic valves have been developed to overcome obstructive limitations associated with stented bioprostheses. The aim of the current multiinstitutional study was to compare hemodynamics of transcatheter (TAVR) and the Freedom SOLO Stentless (FS) valve in an intermediate risk population undergoing surgical aortic valve replacement.

Methods: From 2010 to 2014, 420 consecutive patients underwent isolated surgical aortic valve replacement with FS and 375 patients underwent TAVR. Only patients with intermediate operative risk (Society of Thoracic Surgeons score $4-10)$ and small aortic annulus $(\leq 23 \mathrm{~mm})$ were included. After a propensity matched analysis 142 patients in each group were selected. Thirty-day postoperative clinical and echocardiographic parameters were evaluated.

Results: Mean prosthesis diameter was $22.2 \pm 0.9 \mathrm{~mm}$ for FS and $22.4 \pm 1.0 \mathrm{~mm}$ for TAVR. In-hospital mortality was $2.1 \%$ for FS and $6.3 \%$ for TAVR $(P=.02)$. Postoperative FS peak gradients were $19.1 \pm 9.6 \mathrm{~mm} \mathrm{Hg}$ (mean $10.8 \pm 5.9 \mathrm{~mm}$ $\mathrm{Hg}$ ); TAVR peak gradients were $20.2 \pm 9.5 \mathrm{~mm} \mathrm{Hg}$ (mean $10.7 \pm 6.9 \mathrm{~mm} \mathrm{Hg}$ ) $P=.57(P=.88)$. Postoperative effective orifice area was $1.93 \pm 0.52 \mathrm{~cm}^{2}$ for FS and $1.83 \pm 0.3 \mathrm{~cm}^{2}$ for TAVR $(P=.65)$. There was no prostheses-patient mismatch in either group. Postoperative grade 2-3 paravalvular leak was present in $3.5 \%$ for TAVR and $0.7 \%$ for FS. Postoperative permanent pacemaker implant rate was $12 \%$ for TAVR and only 1 case $(0.7 \%)$ in the FS group $(P<.001)$.

Conclusions: In patients with small aortic annulus and intermediate risk, both FS and TAVR demonstrated similar excellent hemodynamic performance. TAVR demonstrated greater mortality and rates of pacemaker insertion. Further studies are warranted to validate TAVR indications in this subset of patients. ( $\mathrm{J}$ Thorac Cardiovasc Surg 2017;153:549-58)

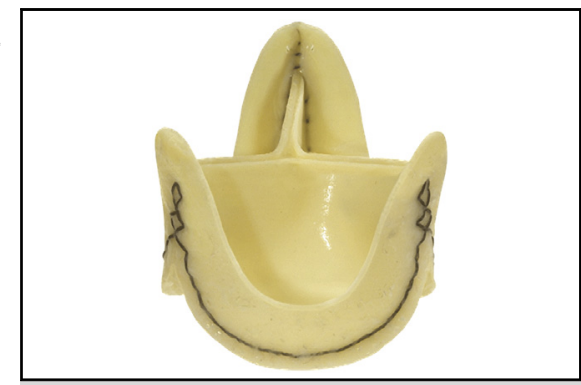

The Freedom SOLO pericardial stentless valve.

Central Message

In patients with small aortic annuli and intermediate risk, Freedom SOLO stentless valve shows excellent hemodynamics, similar to transcatheter aortic valve replacement, with better outcomes.

\section{Perspective}

The use of transcatheter aortic valve replacement negatively affects the perioperative outcome with significantly greater early mortality, greater incidence of periprosthetic regurgitation and postprocedural atrioventricular block requiring pacemaker implant. Further studies are warranted to validate transcatheter aortic valve replacement indications in patients with intermediate-low risk profile and small aortic annulus.

See Editorial Commentary page 559.

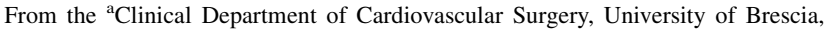
Brescia, Italy; ${ }^{b}$ Cardiology Unit, Cliniche Humanitas Gavazzeni, Bergamo, Italy; ${ }^{c}$ Department of Cardiovascular Surgery, Charité - Universitätsmedizin Berlin, Berlin, Germany; ${ }^{\mathrm{d}}$ Department of Cardiac Surgery, CHU de Nancy, Nancy, France; 'Division of Cardiac Surgery, Queen's University, Kingston General Hospital, Kingston, Ontario, Canada; ${ }^{\mathrm{f}}$ Department of Cardiac Surgery, Paracelsus Medical University Nuremberg, Nuremberg, Germany; ${ }^{g}$ Department of Cardiac Surgery, University of Bologna, Bologna, Italy; and ${ }^{\mathrm{h}}$ Department of Cardiac Surgery, Institut Mutualiste Montsouris, Paris, France.

Read at the 96th Annual Meeting of The American Association for Thoracic Surgery, May 14-18, 2016, Baltimore, Maryland.

Received for publication May 28, 2016; revisions received Sept 30, 2016; accepted for publication Oct 16, 2016; available ahead of print Dec 8, 2016.

Address for reprints: Alberto Repossini, MD, Cardiac Surgery Unit University of Brescia, Spedali Civili, Piazza Spedali Civili 1, 25123 Brescia, Italy (E-mail: arepossini@yahoo.it).

$0022-5223 / \$ 36.00$

Copyright (c) 2016 by The American Association for Thoracic Surgery

http://dx.doi.org/10.1016/j.jtcvs.2016.10.086
The recently published Placement of Aortic Transcatheter Valves (PARTNER) 2 Trial $^{1}$ concluded that clinical outcomes for transcatheter aortic valve replacement (TAVR) were similar to surgical aortic valve replacement (sAVR) with respect to the primary end point of death or disabling stroke in patients with an intermediate-risk profile. Despite

Scanning this QR code will take you to supplemental figure, tables, and video for this article. To view the AATS 2016 Webcast, see the URL next to the video thumbnail.

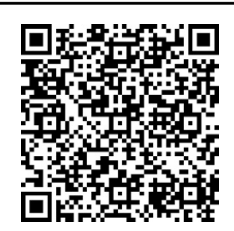




$\begin{array}{ll}\text { Abbreviations and Acronyms } \\ \text { AVR } & =\text { aortic valve replacement } \\ \text { CI } & =\text { confidence interval } \\ \text { FS } & =\text { Freedom SOLO } \\ \text { OR } & =\text { odds ratio } \\ \text { PARTNER }=\text { Placement of Aortic Transcatheter } & \text { Valves } \\ \text { PM } & =\text { pacemaker } \\ \text { PPM } & =\text { prostheses-patient-mismatch } \\ \text { PVL } & =\text { paravalvular leak } \\ \text { SAVR } & =\text { surgical aortic valve replacement } \\ \text { STS } & =\text { Society of Thoracic Surgeons } \\ \text { TAVR } & =\text { transcatheter aortic valve replacement }\end{array}$

the findings of this landmark prospective randomized trial, however, this study included a heterogeneous population of patients in the surgical group, particularly in regard to the type of surgical prosthesis used and procedures.

Furthermore, the hemodynamic performance of stented valves could lead to a greater likelihood of patientprosthesis mismatch (PPM), thus leading to a potential overestimation of the hemodynamic advantages of TAVR in this specific subset of patients. In patients with small aortic annulus, for example, a greater incidence of PPM associated with greater early and late mortality has been reported, mainly when ventricular function is reduced. ${ }^{2-4}$ In such cases stentless prostheses provide excellent hemodynamic results compared with stented prostheses, ${ }^{5-7}$ possibly with improved long-term durability and reduced long-term mortality rates. ${ }^{8}$ The routine use of stentless bioprostheses for sAVR, however, is still limited, despite the well-known superior hemodynamic performances compared with stented bioprostheses, ${ }^{2,9,10}$ which continues to be the gold standard treatment in low- and intermediate-risk aortic stenosis patients older than 65 years of age.

During the past decade, the use of TAVR in patients with severe aortic stenosis and high operative risk has been shown to be a reasonable alternative to conventional sAVR in patients with prohibitive surgical risk. ${ }^{11,12}$ Nevertheless, an ongoing debate continues regarding the best operative strategy for intermediate-risk patients for whom sAVR demonstrates superior results compared with TAVR in terms of postoperative morbidity and mortality. ${ }^{13,14}$ Since their introduction into clinical practice, concerns exist regarding TAVR performance due to a "left-in-place" calcified native valve; however, recent studies have demonstrated low transprosthetic gradients at early and mid-term, even in patients with small aortic annuli. ${ }^{15}$ Given the favorable hemodynamic performance of stentless valves and the paucity of data comparing such prostheses with transcatheter valves, we sought to investigate the performance and clinical outcomes of stentless sAVR versus TAVR in a population of patients with isolated, severe aortic valve stenosis and an intermediate-risk profile.

\section{METHODS \\ Study Population}

The present study was an observational, retrospective, multicenter cohort study in 795 consecutive patients with isolated severe aortic valve stenosis and an intermediate-risk profile (Society of Thoracic Surgeons [STS] Predictive of Mortality $4 \%-10 \%)^{16,17}$ undergoing sAVR or TAVR after multidisciplinary Heart Team evaluation. Data were collected from 7 European cardiac centers, including data for demographic characteristics, comorbidities, and comprehensive information regarding the type of intervention. All centers were selected according to their high-volume activity either in stentless valve surgery and TAVR procedures. The institutional review board of the University of Brescia approved this retrospective analysis of clinically acquired data, and informed consent for anonymous data treatment for scientific purposes was obtained.

From May 2010 to December 2014, 795 patients with isolated severe aortic valve stenosis and an intermediate-risk profile with aortic annulus $\leq 23 \mathrm{~mm}$, underwent aortic valve replacement (AVR); 420 patients underwent SAVR with the bovine pericardial stentless bioprosthesis Freedom SOLO (FS) valve (Sorin Group, Milan, Italy; Figure 1), whereas 375 patients were treated by TAVR. Preoperative patient characteristics are listed in Table 1. A propensity score matching analysis was performed to reduce selection bias. Following 1:1 propensity-score matching, 142 patients from each treatment group were selected to obtain 2 homogeneous populations (Table 2). Transthoracic echocardiographic baseline assessment was performed in every patient (Table 3). Transesophageal echocardiography or stress echocardiography was performed only in cases of low-flow stenosis that required further evaluations. Predischarge transthoracic echocardiography was performed in every patient (Table 3).

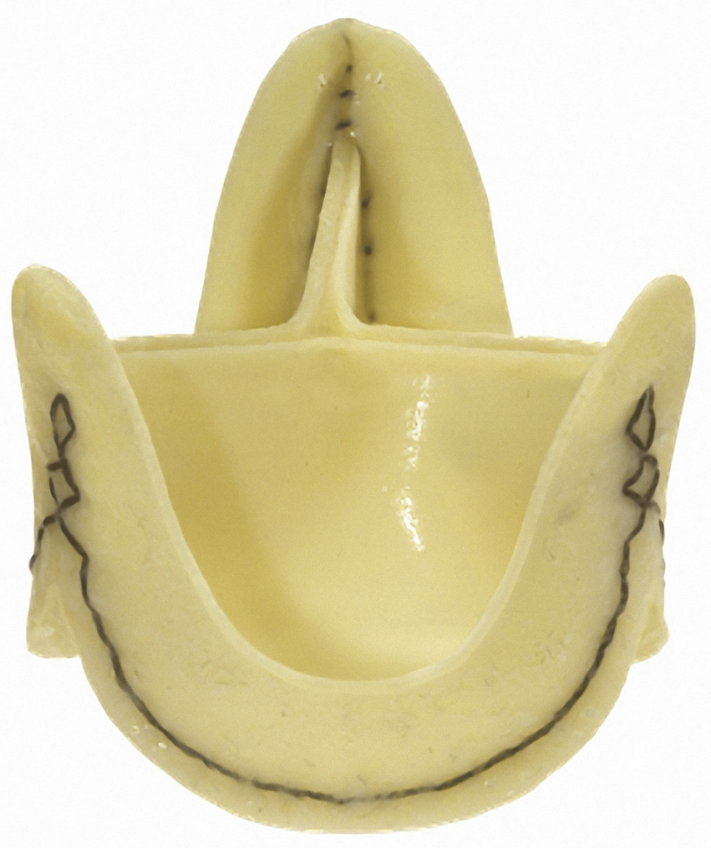

FIGURE 1. Freedom SOLO pericardial stentless valve. 
TABLE 1. Baseline unmatched group characteristics

\begin{tabular}{|c|c|c|c|}
\hline & $\underline{\text { FS group, } n=420}$ & $\underline{\text { TAVR group, } \mathrm{n}=\mathbf{3 7 5}}$ & \\
\hline Characteristcs & n $(\%)$ & n $(\%)$ & $P$ value \\
\hline Age, $y$, mean \pm SD & $75 \pm 8.2$ & $79 \pm 6.8$ & .007 \\
\hline Female sex & $173(41.2)$ & $179(47.7)$ & .742 \\
\hline NYHA III-IV & $187(44.5)$ & $259(69)$ & $<.001$ \\
\hline $\mathrm{BMI}, \mathrm{kg} / \mathrm{m}^{2}$, mean $\pm \mathrm{SD}$ & $26.3 \pm 4.7$ & $26 \pm 1.2$ & .856 \\
\hline BMI $>30 \mathrm{~kg} / \mathrm{m}^{2}$ & $79(18.8)$ & $73(19.5)$ & .857 \\
\hline $\mathrm{BSA}, \mathrm{m}^{2}$ & $1.73 \pm 0.18$ & $1.71 \pm 0.17$ & .752 \\
\hline Diabetes & $116(27.6)$ & $111(29.7)$ & .582 \\
\hline Dyslipidemia & $141(33.6)$ & $148(39.7)$ & .090 \\
\hline Hypertension & $263(62.6)$ & $276(73.6)$ & .001 \\
\hline Severe COPD $\left(\mathrm{FEV}_{1}<50 \%\right)$ & $55(13)$ & $78(20.8)$ & .004 \\
\hline PAD & $62(12.8)$ & $95(25.3)$ & $<.001$ \\
\hline Recent MI & $34(8.1)$ & $30(8.1)$ & 1.000 \\
\hline Previous CVA & $32(7.6)$ & $48(12.8)$ & .018 \\
\hline CRF (GFR < $30 \mathrm{~mL} / \mathrm{min})$ & $50(11.9)$ & $144(38.4)$ & $<.001$ \\
\hline LVEF, $\%$, mean \pm SD & $55 \pm 11$ & $52.9 \pm 13.2$ & .045 \\
\hline LVEF $30 \%-50 \%$ & $116(27.6)$ & $139(37)$ & .005 \\
\hline $\mathrm{LVEF}<30 \%$ & $14(3.3)$ & $29(7.8)$ & .007 \\
\hline PAPs $>30 \mathrm{~mm} \mathrm{Hg}$ & $99(23.5)$ & $170(45.3)$ & $<.001$ \\
\hline Permanent PM & $12(2.8)$ & $17(4.5)$ & .256 \\
\hline Reoperation & $5(1.2)$ & $49(20.8)$ & $<.001$ \\
\hline Endocarditis & $19(4.5)$ & $7(1.8)$ & .045 \\
\hline Frailty (5-m walk test time $>7 \mathrm{~s}$ ) & $98(23.3 \%)$ & $102(27.2 \%)$ & .190 \\
\hline STS score & $6.8 \pm 4.2$ & $9.9 \pm 3.2$ & .009 \\
\hline
\end{tabular}

FS, Freedom SOLO; TAVR, transcatheter aortic valve replacement; $N Y H A$, New York Heart Association; $B M I$, body mass index; $B S A$, body surface area; $C O P D$, chronic obstructive pulmonary disease; $F E V_{l}$, forced expiratory volume first second; $P A D$, peripheral artery disease; $M I$, myocardial infarction; $C V A$, cerebrovascular accident; $C R F$, chronic renal failure; GFR, glomerular filtration rate; $L V E F$, left ventricular ejection fraction; PAPS, systolic pulmonary artery pressure; PM, pacemaker; STS, Society of Thoracic Surgeons.

The approach of sAVR versus TAVR was adopted after a multidisciplinary evaluation including preoperative risk assessment (STS score) and additional findings such as frailty, anatomy, and peripheral atherosclerotic disease.

\section{Surgical Technique}

FS valve implantation. The characteristics of the FS valve have been reported previously. ${ }^{18}$ FS is manufactured from 2 bovine pericardial sheets without a sewing ring stent. Its unique design allows for efficient implantation in a supra-annular position with a running suture. The operative approach was via full midline sternotomy $(74 \%)$ or by upper "J-shaped" mini-sternotomy as a minimally invasive approach (26\%). Myocardial protection was achieved with cold crystalloid or blood cardioplegia delivered antegrade or retrograde. Transverse aortotomy was performed approximately $1 \mathrm{~cm}$ above the sinotubular junction, and the aortic valve was excised with debridement of the annulus. Valve size selection was made corresponding to the sizer that comfortably passed through the annulus. Valve implantation was performed, in a supra-annular subcoronary position with three 4-0 polypropylene sutures constructed as a single continuous suture line (Video 1). ${ }^{18}$ After the patient was weaned from cardiopulmonary bypass, transoesophageal echocardiography was performed to assess valve function.

\section{TAVR Procedure}

TAVR was performed by the transfemoral route in the majority of patients $(273 / 375,72.8 \%)$, followed by a transapical approach $(84 / 375$, $22.4 \%)$ or other transvascular approach $(18 / 375,4.8 \%)$ : No case of direct aortic access was recorded in the TAVR cohort after the matching process.
The implanted prosthesis was a CoreValve (Medtronic, Minneapolis, Minn; 228/375, 61\%) self-expandable prosthesis or balloon-expandable SAPIEN XT (Edwards Lifesciences, Irvine, Calif; 134/375, 35.7\%) or Acurate TA (Symetis SA, Lausanne, Switzerland; 13/375, 3.3\%). For the balloon-expandable valve, 20- and 23-mm valves were selected for 19and 21-mm aortic annuli, respectively; a 26-mm valve was used if the aortic annulus was 22 to $23 \mathrm{~mm}$. For the self-expandable valve, a 26-mm valve was selected if the aortic annulus was 19 to $23 \mathrm{~mm}$. Size S of the Accurate TA was chosen for 21 to 23 measured annulus.

After valve deployment, the presence and severity of aortic regurgitation was assessed visually by determination of the relative amount of radiographic contrast medium in the ventricle after injection into the proximal aorta and classified using a scale of 0 to 4 . Balloon dilatation was performed in cases of significant paravalvular leak (PVL), defined as PVL of grade 2 or greater and then reassessed with contrast injection and transesophageal echocardiography.

Endpoints of the study. Primary endpoints were 30-day mortality (valve- and cardiac-related mortality) and hemodynamic performance: peak and mean gradients, effective orifice area, severe PPM (indexed effective orifice area $\left.<0.65 \mathrm{~cm}^{2} / \mathrm{m}^{2}\right),{ }^{19}$ and PVL $\geq$ grade II. Secondary endpoints included the incidence of perioperative complications such as myocardial infarction, cerebrovascular accidents and major hemorrhagic events, atrioventricular blocks requiring pacemaker (PM) implantation, acute kidney failure, and respiratory complications, according to Valve Academic Research Consortium 2 Criteria. ${ }^{16}$

Statistical analysis. Pre- and postoperative variables were analyzed with the $t$ test for quantitative variables and the Fisher exact test for qualitative variables; values for quantitative variables are expressed as mean \pm standard deviation. Survival curves were evaluated by means of 
TABLE 2. Baseline matched group characteristics

\begin{tabular}{|c|c|c|c|}
\hline Characteristics & $\frac{\text { FS group, } n=142}{n(\%)}$ & $\frac{\text { TAVR group, } n=142}{n(\%)}$ & $P$ value \\
\hline Age, $y$, mean $\pm S D$ & $76.4 \pm 7.2$ & $76.2 \pm 7.6$ & .782 \\
\hline Female sex & $54(38.1)$ & $57(40.1)$ & .808 \\
\hline NYHA III-IV & $69(48.6)$ & $67(47.2)$ & .905 \\
\hline BMI, $\mathrm{kg} / \mathrm{m}^{2}$, mean $\pm \mathrm{SD}$ & $25.7 \pm 3.1$ & $25.6 \pm 1.9$ & .625 \\
\hline $\mathrm{BMI}>30 \mathrm{~kg} / \mathrm{m}^{2}$ & $22(15.5)$ & $24(16.9)$ & .872 \\
\hline $\mathrm{BSA}, \mathrm{m}^{2}$ & $1.61 \pm 0.15$ & $1.63 \pm 0.21$ & .596 \\
\hline Diabetes & $43(30.2)$ & $41(28.9)$ & .897 \\
\hline Dyslipidemia & $51(35.9)$ & $49(34.5)$ & .901 \\
\hline Hypertension & $84(59.2)$ & $86(60.6)$ & .904 \\
\hline Severe COPD $\left(\mathrm{FEV}_{1}<50 \%\right)$ & $16(11.2)$ & $17(12.0)$ & 1.000 \\
\hline PAD & 19 (13.3) & $21(14.8)$ & .865 \\
\hline Recent MI & $10(7.0)$ & $11(7.7)$ & 1.000 \\
\hline Previous CVA & $12(8.4)$ & $13(9.1)$ & 1.000 \\
\hline $\mathrm{CRF}(\mathrm{GFR}<30 \mathrm{~mL} / \mathrm{min})$ & $16(11.2)$ & $21(14.7)$ & .481 \\
\hline LVEF, \%, mean \pm SD & $53 \pm 12.9$ & $52.9 \pm 14.1$ & .528 \\
\hline LVEF $30 \%-50 \%$ & $37(26.1)$ & $42(29.5)$ & .596 \\
\hline LVEF $<30 \%$ & $4(2.8)$ & $7(4.9)$ & .541 \\
\hline PAPs $>30 \mathrm{~mm} \mathrm{Hg}$ & $36(25.3)$ & $39(27.4)$ & .788 \\
\hline Permanent PM & $5(3.5)$ & $6(4.2)$ & 1.000 \\
\hline Frailty (5-m walk test time $>7 \mathrm{~s}$ ) & $35(24.6 \%)$ & $36(25.3 \%)$ & .892 \\
\hline Reoperation & $3(2.1)$ & $8(5.6)$ & .217 \\
\hline Endocarditis & $7(4.9)$ & $4(2.8)$ & .541 \\
\hline STS score & $6.7 \pm 3.2$ & $7.2 \pm 2.9$ & .074 \\
\hline
\end{tabular}

FS, Freedom SOLO; TAVR, transcatheter aortic valve replacement; $N Y H A$, New York Heart Association; $B M I$, body mass index; $B S A$, body surface area; $C O P D$, chronic obstructive pulmonary disease; $F E V_{1}$, forced expiratory volume first second; $P A D$, peripheral artery disease; $M I$, myocardial infarction; $C V A$, cerebrovascular accident; $C R F$, chronic renal failure; $G F R$, glomerular filtration rate; $L V E F$, left ventricular ejection fraction; $P A P S$, systolic pulmonary artery pressure; $P M$, pacemaker; STS, Society of Thoracic Surgeons.

Kaplan-Meier analysis. A $P$ value less than .05 was considered significant. A binary logistic regression model was used to develop a propensity score for each patient. The variables included in the propensity score model were age, STS score, body mass index, female sex, hypertension, dyslipidemia, chronic obstructive pulmonary disease, previous percutaneous coronary intervention, previous myocardial infarction, coronary artery disease, cerebrovascular accident, peripheral arterial disease, diabetes, New York Heart Association III-IV, chronic renal insufficiency, reoperation, and ejection fraction. We derived propensity scores including pretreatment variables that were associated at $P<.10$ in a multivariable model. Nearestneighbor propensity score matching subsequently was used to match 1:1 patients ${ }^{20}$ in the sAVR group and TAVR group. Matching was performed using calipers of width of 0.2 of the standard deviation of the logit of propensity score. Hosmer-Lemeshow test was performed to assess the goodness-of-fit of propensity-match model $(P=.204)$. The propensity scores distribution after matching was assessed graphically with histograms (Figure 2). As described in recent JTCVS statistical commentaries, the matched standardized differences of each covariate were less than $10 \%$, thus proofing the comparability between the 2 groups (Figure E1). ${ }^{21,22} \mathrm{We}$ performed a stabilized inverse probability weighting analysis on the entire cohort as a sensitivity analysis ${ }^{23}$ to confirm the robustness of results obtained (Table E1).

Univariate and multivariate logistic regression analysis was performed to identify independent predictors of mortality among preoperative characteristics identified from propensity score model associated to the dependent variable (Table 4). Outcomes were adjusted for site performing a regression model with a backward logistic strategy with a removal $P$ value $<.20$. Characteristics of unmatched patients and their outcomes were reported as Tables E2 to E4. The statistical package used was SPSS software (Version 23; IBM Corp, New York, NY).

\section{RESULTS}

\section{Preoperative Characteristics}

Baseline characteristics of patients who underwent SAVR with FS valve $(n=420)$ and TAVR $(n=375)$ are listed in Table 1. Patients undergoing TAVR were older compared with those receiving FS implantation (FS group: $75 \pm 8.2$ years vs TAVR: $79 \pm 6.8$ years; $P=.007$ ) and the STS score was significantly greater in patients undergoing TAVR (FS group: $6.8 \% \pm 4.2 \%$ vs TAVR: $9.9 \%$ $\pm 3.2 \% ; P=.009)$ before matching. No differences were reported concerning aortic valve area (planimetric and indexed), and transvalvular peak/mean gradients. Frailty assessment was defined as "5-meter walk test time $>7$ seconds," and its incidence was similar before (23.3\% SOLO vs $27.2 \%$ TAVR $P=.190$ ) and after matching $(24.6 \%$ SOLO vs $25.3 \%$ TAVR $P=.892)$.

\section{Operative Results}

Operative results are listed in Table 3. Of note only a single patient had an emergency procedure in the sAVR group $(0.7 \%)$ for active infectious endocarditis with acute heart failure unresponsive to medical therapy. Five patients $(3.5 \%)$ in the TAVR group had an emergency procedure, 3 patients for acute heart failure requiring intra-aortic balloon pump support and 2 patients for cardiac arrest 


\begin{tabular}{|c|c|c|c|}
\hline & $\frac{\text { FS group, } n=142}{n(\%)}$ & $\frac{\text { TAVR group, } n=142}{n(\%)}$ & $P$ value \\
\hline \multicolumn{4}{|l|}{ Preoperative ECHO } \\
\hline Peak transvalvular gradient, $\mathrm{mm} \mathrm{Hg}$ & $79.9 \pm 30.7$ & $77.9 \pm 20.8$ & .084 \\
\hline Mean transvalvular gradient, $\mathrm{mm} \mathrm{Hg}$ & $48.7 \pm 18.2$ & $48.4 \pm 14.5$ & .122 \\
\hline $\mathrm{EOA}, \mathrm{cm}^{2}$ & $0.71 \pm 0.2$ & $0.67 \pm 0.1$ & .017 \\
\hline EOAI, $\mathrm{cm}^{2} / \mathrm{m}^{2}$ & $0.39 \pm 0.17$ & $0.38 \pm 0.32$ & .858 \\
\hline Annular diameter, $\mathrm{mm}$ & $22.2 \pm 1.3$ & $21.8 \pm 1.4$ & .354 \\
\hline Emergency surgery & $1(0.7)$ & $5(3.5)$ & .837 \\
\hline MAV $>48 \mathrm{~h}$ & $3(2.1)$ & $2(1.4)$ & .438 \\
\hline ICU stay, $d$, mean \pm SD & $1.6 \pm 1.8$ & $3.2 \pm 2$ & .011 \\
\hline Mean valve diameter & $22.2 \pm 0.9$ & $22.4 \pm 1.0$ & .863 \\
\hline $\mathrm{CPB}$ time, min, mean $\pm \mathrm{SD}$ & $79 \pm 12$ & - & \\
\hline Aortic cross-clamp time, min, mean $\pm \mathrm{SD}$ & $67 \pm 15$ & - & \\
\hline Transapical TAVR & - & $25(17.6)$ & \\
\hline Other TAVR approaches & - & $8(3.6)$ & \\
\hline \multicolumn{4}{|l|}{ Postoperative TTE } \\
\hline Peak transvalvular gradient, $\mathrm{mm} \mathrm{Hg}$ & $19.1 \pm 9.6$ & $20.2 \pm 9.5$ & .572 \\
\hline Mean transvalvular gradient, $\mathrm{mm} \mathrm{Hg}$ & $10.8 \pm 5.9$ & $10.7 \pm 6.9$ & .884 \\
\hline $\mathrm{EOA}, \mathrm{cm}^{2}$ & $1.93 \pm 0.52$ & $1.89 \pm 0.3$ & .651 \\
\hline EOAI, $\mathrm{cm}^{2} / \mathrm{m}^{2}$ & $1.12 \pm 0.22$ & $1.02 \pm 0.31$ & .738 \\
\hline Severe PPM & $0(0.0)$ & $0(0.0)$ & 1.000 \\
\hline PVL $\geq$ grade II & $1(0.7)$ & $5(3.5)$ & .534 \\
\hline
\end{tabular}

FS, Freedom SOLO; TAVR, transcatheter aortic valve replacement; TTE, transthoracic echocardiography; EOA, effective orifice area; EOAI, EOA index; MAV, mechanicalassisted ventilation; $I C U$, intensive care unit; $C P B$, cardiopulmonary bypass; $P P M$, prostheses-patient mismatch; $P V L$, perivalvular leak.

requiring emergency aortic balloon valvuloplasty followed by TAVR procedure $(P=.837)$. In the postmatch sAVR series of patients, 109 patients received a 23 -mm prosthesis, 24 patients had a $21-\mathrm{mm}$ prosthesis, and 9 patients received a 19-mm FS. In the TAVR group, 80 Medtronic CoreValve prostheses were implanted: 73 patients received a $23-\mathrm{mm}$ prosthesis and 7 patients received a 26-mm prosthesis. Among 58 patients receiving the Edwards SAPIEN, 23 received a $20-\mathrm{mm}$ prosthesis, 29 received a $23-\mathrm{mm}$ prosthesis, and 6 received a 26-mm prosthesis. Four patients had an Accurate Symetis TA. In 10 patients $(7.1 \%)$ a valve-in-valve procedure was necessary after TAVR as the result of prosthesis malpositioning (7 CoreValve, 3 Edwards SAPIEN). No early reoperation was reported in sAVR group. No other early reintervention was required for sAVR or TAVR cohorts. No patient undergoing sAVR had

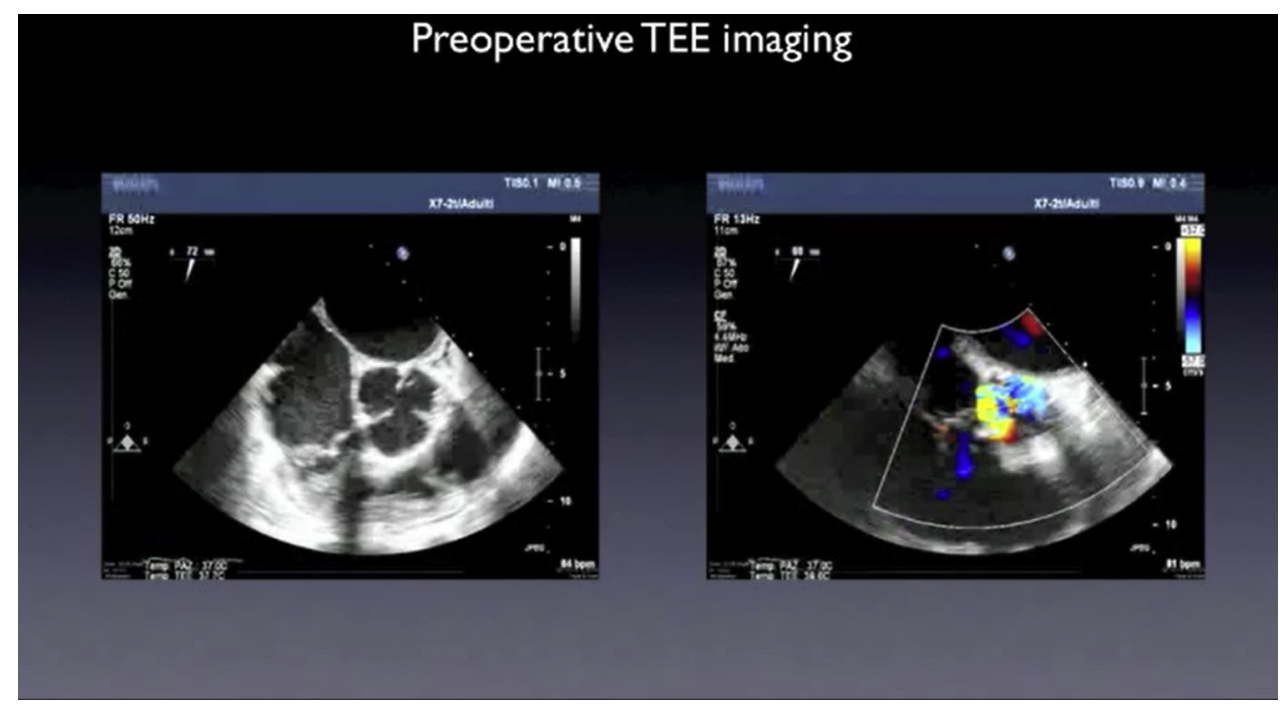

VIDEO 1. Surgical implant of a Freedom SOLO bovine pericardial stentless valve via right J-shaped ministernotomy. Case report of severe aortic valve regurgitation in acute endocarditis. TEE, Transesophageal echocardiography. Video available at: http://www.jtcvsonline.org/article/S0022-5223(16)314945/addons. 


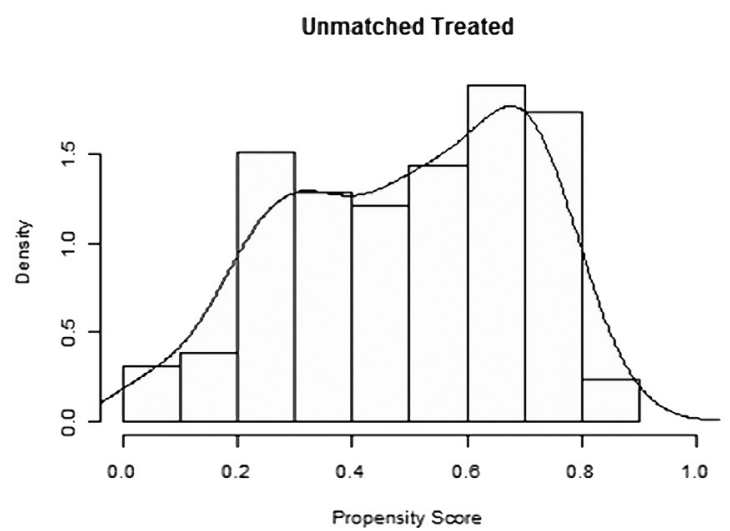

Unmatched Control

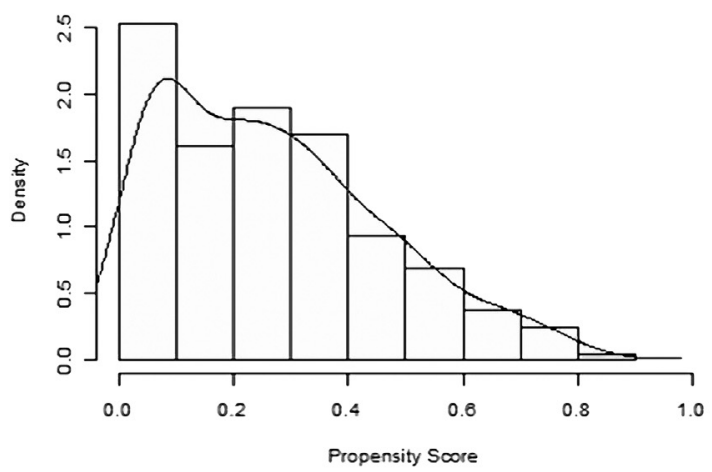

Matched Treated

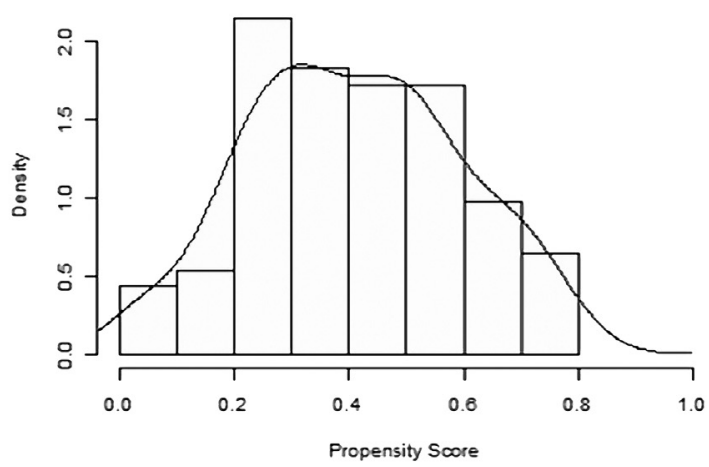

Matched Control

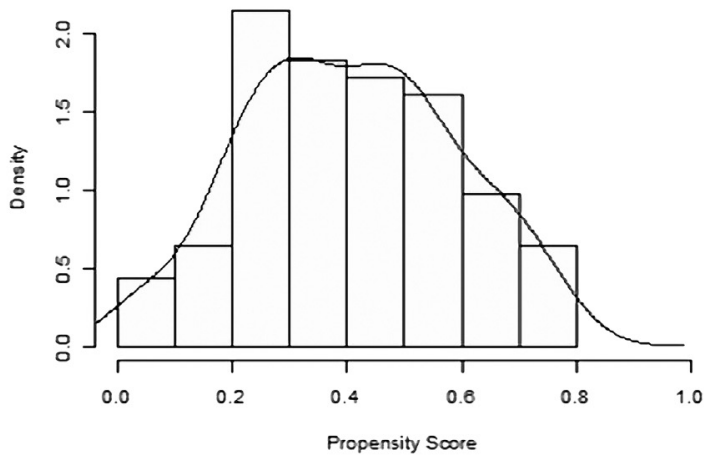

FIGURE 2. Propensity score distribution in the prematch groups (case: SOLO group; controls: TAVR group), and postmatch groups (case: SOLO group; controls: TAVR group).

an associated surgical procedure. No patient in the study required additional surgical procedures. Patients in the TAVR group had a significantly longer stay in the intensive care unit (FS group: $1.6 \pm 1.8$ days vs TAVR: $3.2 \pm 2.0$ days; $P=.011$ ) because of the greater incidence of late AV blocks requiring PM implantation.

\section{Postoperative Complications}

Before and after propensity matching, 30-day mortality rate was greater in the TAVR group (mortality prematch:

TABLE 4. Cox regression for all-cause death

\begin{tabular}{lccccccc}
\hline & \multicolumn{3}{c}{ Univariate } & & \multicolumn{3}{c}{ Multivariate } \\
\cline { 2 - 4 } \cline { 7 - 8 } & OR & $\mathbf{9 5} \% \mathbf{C I}$ & $\boldsymbol{P}$ value & & OR & $\mathbf{9 5} \%$ CI & $\boldsymbol{P}$ value \\
\hline Diabetes & 1.4 & $0.8-1.9$ & & & & \\
CRF & 2.2 & $1.3-3.6$ & .001 & 2.6 & $1.7-3.9$ & $<.001$ \\
Age & 1.9 & $0.9-2.8$ & & & & \\
TAVR vs FS & 2.6 & $1.7-4.1$ & $<.001$ & & 3.7 & $2.1-4.7$ & $<.001$ \\
COPD & 1.3 & $0.5-1.6$ & & & & \\
Previous CVA & 1.6 & $0.9-1.7$ & & & & \\
REDO & 1.2 & $0.6-1.8$ & & & & \\
\hline
\end{tabular}

$O R$, Odds ratio; $C I$, confidence interval; $C R F$, chronic renal failure; TAVR, transcatheter aortic valve replacement; $F S$, Freedom SOLO; COPD, chronic obstructive pulmonary disease; $C V A$, cerebrovascular accident.
$2.8 \%$ FS group vs $7.5 \%$ TAVR group, $P=.003$; mortality postmatch: $2.1 \%$ vs $6.3 \%, P=.021$ ). In the prematch series, valve-related death and cardiac death were greater in the TAVR group; after matching they remained greater, although this was not statistically significant (Table 5). No valve-related death was reported at 30 days in FS group, whereas 7 patients had a valve-related death in the TAVR group $(P=.005)$, in 4 cases as the result of valve malpositioning and embolization requiring emergency cardiac surgery and in 3 cases as the result of annular rupture with fatal bleeding. In the TAVR group, there was also a grater incidence of acute kidney injury (2.6\% in FS group vs $6.1 \%$ in TAVR group, $P=.025$ postmatch) and continuous venovenous hemofiltration ( 2.1 vs 3.2 respectively, $P=.069$ postmatch).

PM implantation was greater in the TAVR group both in prematch and postmatch series $(12 \%$ vs $0.7 \%, P<.001$ postmatch). No peripheral vascular complications were reported in the sAVR group, whereas 10 patients had major vascular complications in the TAVR group $(P=.002$ postmatch). A greater incidence of postprocedural cerebrovascular accident was reported in the TAVR group, although not statistically significant $(2.8 \%$ vs $1.4 \%, P=.684$ postmatch). Univariate and multivariate regression analyses 
TABLE 5. Postoperative complications (prematch/matched populations)

\begin{tabular}{|c|c|c|c|c|c|c|}
\hline & \multicolumn{3}{|c|}{ Prematch } & \multicolumn{3}{|c|}{ Postmatch } \\
\hline & $\begin{array}{c}\text { FS group, } \\
\mathbf{n}=\mathbf{4 2 0} \\
\end{array}$ & $\begin{array}{c}\text { TAVR group, } \\
\mathbf{n}=\mathbf{3 7 5} \\
\end{array}$ & & $\begin{array}{c}\text { FS group, } \\
\mathrm{n}=142\end{array}$ & $\begin{array}{c}\text { TAVR group, } \\
\mathbf{n}=142 \\
\end{array}$ & \\
\hline & n $(\%)$ & n $(\%)$ & $P$ value & n $(\%)$ & n $(\%)$ & $P$ value \\
\hline 30-d mortality & $12(2.8)$ & $28(7.5)$ & .003 & $3(2.1)$ & $9(6.3)$ & .021 \\
\hline Valve-related death & $0(0.0)$ & $7(1.9)$ & .005 & $0(0.0)$ & $2(1.4)$ & .122 \\
\hline Cardiac death & $5(1.1)$ & $19(5.1)$ & .002 & $1(0.7)$ & $5(3.5)$ & .534 \\
\hline Annular rupture & $0(0.0)$ & $3(0.8)$ & .082 & $0(0.0)$ & $2(1.4)$ & .096 \\
\hline CVA & $9(2.1)$ & $15(4.0)$ & .148 & $2(1.4)$ & $4(2.8)$ & .684 \\
\hline Perioperative AMI & $1(0.2)$ & $6(1.6)$ & .061 & $0(0.0)$ & $0(0.0)$ & 1.000 \\
\hline Postoperative PBRC & $120(28.6)$ & $126(33.6)$ & .144 & $36(25.4)$ & $49(34.5)$ & .121 \\
\hline Acute renal failure & $22(5.4)$ & $41(10.9)$ & .004 & $11(2.6)$ & $23(6.1)$ & .025 \\
\hline $\mathrm{CVVH}$ & $6(1.5)$ & $22(5.8 \%)$ & .001 & $3(2.1)$ & $12(3.2)$ & .069 \\
\hline AVB requiring PM implantation & $4(1.0)$ & $47(12.5)$ & $<.001$ & $1(0.7)$ & $17(12.0)$ & $<.001$ \\
\hline ARDS & $6(1.5)$ & $16(4.3)$ & .016 & $2(1.4)$ & $11(7.7)$ & .020 \\
\hline Peripheral vascular complications & $0(0.0)$ & $37(9.8)$ & $<.001$ & $0(0.0)$ & $10(7.4)$ & .002 \\
\hline Sepsis & $10(2.4)$ & $19(5.1)$ & .072 & $3(2.1)$ & $5(3.5)$ & .723 \\
\hline
\end{tabular}

FS, Freedom SOLO; TAVR, transcatheter aortic valve replacement; $C V A$, cerebrovascular accident; $A M I$, acute myocardial infarction; $P B R C$, packed red-blood cells; $C V V H$, continuous venous-venous hemofiltration; $A V B$, atrioventricular block; $P M$, pacemaker; $A R D S$, acute respiratory distress syndrome.

were performed to establish independent predictors of mortality: chronic renal failure (odds ratio [OR], 2.6; 95\% confidence interval $[\mathrm{CI}], 1.7-3.9, P<.001)$ and TAVR approach (OR, 3.7; 95\% CI, 2.1-4.7, $P<.001$ ) were identified as independent predictors of mortality by multivariate analysis. After adjustment for site, treatment strategy significantly affect outcomes (OR, 4.1; 95\% CI, 2.03-8.59, $P<.001$ ). Sensitivity analysis performed with stabilized inverse probability weighting method on survival confirms the results obtained on the propensity matched courts (OR, 3.8; 95\% CI, 1.3-10.7, $P<.012$ ) (Table E1).

\section{Postoperative Echocardiographic Evaluation}

The Doppler echocardiographic data at hospital discharge are listed in Table 3. Predischarge transthoracic echocardiography has been performed routinely in every patient ( $1.6 \%$ missing data).

The peak and mean transprosthetic gradients were similar at discharge in the TAVR group compared with the sAVR group $(P=.572$ and $P=.884$, respectively), as were the aortic valve area and aortic valve area index $(P=.651$ and $P=.738$, respectively). There was no severe PPM in either group. At least moderate aortic regurgitation was present in $3.5 \%$ of the TAVR patients compared with $0.7 \%$ of the sAVR patients after the procedure $(P=.534)$. Aortic regurgitation was paravalvular in all the cases in the TAVR group.

\section{DISCUSSION}

The present study analyzed hemodynamic performances and postoperative complications of sAVR with FS stentless valve compared with TAVR in intermediate-risk patients with aortic stenosis and a preoperative echocardiographic annulus measurement $\leq 23 \mathrm{~mm}$.
In our series, 30-day mortality after TAVR was similar to several published papers, ${ }^{14,24}$ whereas surgical results were better than previous reports in this specific subset of patients. ${ }^{15,25,26}$ The suggested benefit of surgical AVR on mortality in our study seems to be in contrast with the PARTNER 2 data; we found lower surgical mortality $(2.8 \%$ vs $4.1 \%)$ whereas the TAVR mortality was substantially greater $(7.5 \%$ vs $3.9 \%)$ than in PARTNER 2. Such a discrepancy is probably the result of multiple factors. The unique design characteristics of the FS allow suprannular implantion, reducing the risk of atrioventricular block and concomitant unplanned procedures including aortic root enlargement or replacement, as reported in PARTNER 2. ${ }^{1}$ In our study, the TAVR group included both balloon and self-expandable prostheses; furthermore, given the small annular size, this population would be predicted to be at greater risk for coronary ostia occlusion and annular rupture and the choice of the device might have impacted clinical outcomes. In addition, only isolated AVR have been included in our series, thus reducing potential perioperative complications occurring in the surgical group. Of note, other authors ${ }^{13}$ also observed a lower surgical mortality in intermediate risk patients than that reported in the PARTNER 2 trial. A greater prevalence of concomitant or unplanned procedures in the surgical cohort of the PARTNER 2 trial where concomitant $\mathrm{CABG}$ was required in $14.5 \%$ of patients undergoing sAVR whereas concomitant percutaneous coronary intervention was performed only in $3.9 \%$ of the TAVR group. ${ }^{1}$ Similarly, the greater incidence of permanent PM implantation, PVL, and acute kidney injury in the TAVR group may have been related to the earlier generation technology.

In our study, no severe PPM was observed, and hemodynamic performance was similar in both groups compared with previous publications ${ }^{26}$ reporting better immediate 
results in the TAVR group with comparable results to stentless prostheses reported 3 months after discharge. In particular, although stentless valves offer good hemodynamic outcomes and reduced incidence of PPM, superior outcomes in intermediate risk patients, compared with stented valves, has never been demonstrated, possibly owing to the complexity of stentless implantation and the associated prolonged crossclamp times with previously used stentless valves, which may have negatively biased results. Furthermore, the hemodynamic superiority of stentless aortic bioprostheses is still debated, with available studies reporting conflicting data ${ }^{27-29}$ on PPM incidence in small annuli between $17 \%$ and $58 \%{ }^{25}$ These opposing views also may be related to the different type of stentless prostheses used in various studies, as well as variability in implant techniques (single suture vs subcoronary double suture vs full root implantion). Several studies report that the use of transcatheter valves in this particular subset of patients provides excellent hemodynamic and procedural results, ${ }^{15,25,26}$ albeit a comparison with the FS pericardial stentless bioprosthesis, implanted with a single supra-annular suture technique, has not been performed previously.

Our experience showed that neither cross-clamp time nor periprocedural complications ${ }^{30}$ were increased in our FS cohort compared with conventional prostheses without a downside to surgical complexity, which may be attributable to the unique and relatively simple implantation technique afforded by FS, while providing the excellent hemodynamic performance expected of a stentless valve. Moreover, we found out that in intermediate-risk patients 30day mortality was greater in the TAVR cohort compared with FS, with similar hemodynamic performance in the 2 groups. Given the propensity-matched nature of the study that reduces, selection bias, this greater 30-day mortality of nearly 4 times our surgical cohort seems to be related to the TAVR procedure itself. TAVR prostheses are designed to be deployed in a smaller aortic annulus than the prosthesis, which, because the elastic characteristics of the annulus, can allow moderate prosthesis oversizing. Although this "controlled oversizing" assures the best valve anchoring and fitting in the native annulus, any excessive oversizing may lead to catastrophic postprocedural complications such as annular rupture or more commonly, to atrioventricular conduction disturbances. Moreover, for transcatheter prostheses, oversizing is crucial to prevent significant PVL associated with poor early and late outcomes. ${ }^{31,32}$ The incidence of PVL in the TAVR cohort was lower than reported in the PARTNER trial $(3.5 \%$ vs $12 \%)^{11}$ and consistent with other series. ${ }^{1,25,33}$ The reduced incidence of PVL in smaller aortic annuli suggests that such anatomy may allow for a more appropriate expansion and sealing of the transcatheter valve prostheses within the aortic annulus, albeit with a greater risk of a life-threatening annular rupture.
TAVR is associated with an elevated incidence of atrioventricular block requiring permanent PM implantation, ${ }^{12-14}$ due to compression of the cardiac conduction system, which is mostly absent in the FS group because of implantation via a supra-annular subcoronary suture line, ${ }^{2}$ at some distance from the conduction pathway. Finally, despite the possibility of renal injury caused by cardiopulmonary bypass, the incidence of postoperative renal failure was significantly lower in the FS cohort, suggesting use of iodinated contrast medium and possible embolic events during the TAVR procedure as more important determinants of postprocedure renal dysfunction.

\section{Limitations of the Study}

The main limitation of the study is represented by its retrospective design without prospective randomization responsible for the selection bias in treatment choice. Given the unlikelihood of a randomized trial ever comparing these 2 groups of patients, a propensity-matched comparison reducing, albeit not eliminating, the selection bias in retrospective series, seems to be the most appropriate study design. Because there were no strict and similar criteria for definition of frailty among the participating centers, we decided not to include it in our propensity match model. However frailty, defined as "5 meter walk test time $>7$ seconds," had a similar and equally distributed incidence in the pre- and postmatching groups.

Of note, every TAVR procedure was performed after multidisciplinary (heart team) evaluation. Despite some selection bias that may have been introduced by arbitrary selection regarding the choice of treatment, this study represents a consecutive series of all patients undergoing AVR directed by a multidisciplinary heart team that hopefully mitigates selection bias in patient enrollment while presenting an important "real-world" series of patients.

Site and operator variability should be considered in predischarge transthoracic echocardiographic data evaluation. The impact of missing data has been deemed as minimum, given the observed number of missing data $(1.6 \%$ of total number of postprocedure echo data) and the plausible assumptions of an underneath missing at random mechanism.

\section{CONCLUSIONS}

In patients with small aortic annulus and intermediaterisk profile, both FS and TAVR demonstrated similar excellent hemodynamic performances. Nevertheless, TAVR approach seems to influence, considering all the limitations, the perioperative outcome with significant greater early mortality, greater incidence of prosthetic regurgitation and atrioventricular blocks requiring PM implantation, and a trend through greater PVL rate. Further studies are warranted to validate TAVR indications in patients with an intermediate low risk profile and small aortic annulus. Our results with the FS bioprosthesis 
compare favorably with currently available surgical options and may provide an important alternative to conventional stented bioprostheses in intermediate-risk patients with a small aortic annulus.

\section{Webcast}

You can watch a Webcast of this AATS meeting presentation by going to: http://webcast.aats.org/2016/Video/Wed nesday/05-18-16_Ballroom_I_0730_Repossini-800.mp4.

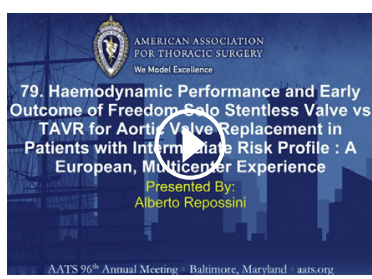

\section{Conflict of Interest Statement}

Alberto Repossini, Herko Grubitzsch, Theodor Fischlein, and Giuseppe Santarpino are consultants for LivaNova. All other authors have nothing to disclose with regard to commercial support.

\section{References}

1. Leon MB, Smith CR, Mack MJ, Makkar RR, Svensson LG, Kodali SK, et al; PARTNER 2 Investigators. Transcatheter or surgical aortic-valve replacement in intermediate-risk patients. N Engl J Med. 2016:374:1609-20.

2. Wollersheim LW, Li WW, Kaya A, Bouma BJ, Driessen AH, van Boven WJ, et al. Stentless versus stented aortic valve bioprostheses in the small aortic root. Semin Thoracic Surg. March 2, 2016 [Epub ahead of print].

3. Blais C, Dumesnil JG, Baillot R, Simard S, Doyle D, Pibarot P. Impact of prosthesis-patient mismatch on short-term mortality after aortic valve replacement. Circulation. 2003;108:983-8.

4. Rao V, Jamieson WRE, Ivanov J, Armstrong S, David TE. Prosthesis patient mismatch affects survival following aortic valve replacement. Circulation. 2000;102:III5-9.

5. Pibarot P, Dumesnil JG, Jobin J, Cartier P, Honos G, Durand LG. Hemodynamic and physical performance during maximal exercise in patients with aortic bioprosthesis valve. Comparison of stentless versus stented bioprosthesis. J Am Coll Cardiol. 1999:34:1609-17.

6. Perez de Arenaza D, Lees B, Flather M, Nugara F, Husebye T, Jasinski M, et al. Randomized comparison of stentless versus stented valves for aortic stenosis. Effects on left ventricular mass. Circulation. 2005;112:2696-702.

7. Ali A, Halstead JC, Cafferty F, Sharples L, Rose F, Coulden R, et al. Are stentless valves superior to modern stented valves? A prospective randomized trial. Circulation. 2006;114:I535-40.

8. Wilbring M, Alexiou K, Schumann E, Matschke K, Tugtekin SM. Isolated aortic valve replacement in patients with small aortic annulus-a high-risk group on long-term follow-up. Thorac Cardiovasc Surg. 2013;61:379-85.

9. Dunning J, Graham RJ, Thambyrajah J, Stewart MJ, Kendall SW, Hunter S. Stentless vs. stented aortic valve bioprostheses: a prospective randomized controlled trial. Eur Heart J. 2007;28:2369-74.

10. Cheng D, Pepper J, Martin J, Stanbridge R, Ferdinand FD, Jamieson WR, et al. Stentless versus stented bioprosthetic aortic valves: a systematic review and meta-analysis of controlled trials. Innovations (Phila). 2009;4: 61-73.

11. Mack MJ, Leon MB, Smith CR, Miller DC, Moses JW, Tuzcu EM, et al; PARTNER 1 trial investigators. 5-year outcomes of transcatheter aortic valve replacement or surgical aortic valve replacement for high surgical risk patients with aortic stenosis (PARTNER 1): a randomised controlled trial. Lancet. 2015;385:2477-84.
12. Adams DH, Popma JJ, Reardon MJ, Yakubov SJ, Coselli JS, Deeb GM, et al; U.S CoreValve Clinical Investigators. Transcatheter aortic-valve replacement with a self-expanding prosthesis. N Engl J Med. 2014;370:1790-8.

13. Muneretto C, Alfieri O, Cesana BM, Bisleri G, De Bonis M, Di Bartolomeo R, et al. A comparison of conventional surgery, transcatheter aortic valve replacement, and sutureless valves in "real-world" patients with aortic stenosis and intermediate- to high-risk profile. J Thorac Cardiovasc Surg. 2015;150:1570-7; discussion 1577-9.

14. Piazza N, Kalesan B, van Mieghem N, Head S, Wenaweser P, Carrel TP, et al. A 3-center comparison of 1-year mortality outcomes between transcatheter aortic valve implantation and surgical aortic valve replacement on the basis of propensity score matching among intermediate-risk surgical patients. JACC Cardiovasc Interv. 2013;6:443-51.

15. Clavel MA, Webb JG, Pibarot P, Altwegg L, Dumont E, Thompson C, et al. Comparison of the hemodynamic performance of percutaneous and surgical bioprostheses for the treatment of severe aortic stenosis. J Am Coll Cardiol. 2009 53:1883-91.

16. Kappetein AP, Head SJ, Généreux P, Piazza N, van Mieghem NM, Blackstone EH, et al. Updated standardized endpoint definitions for transcatheter aortic valve implantation: the Valve Academic Research Consortium-2 consensus document. Eur Heart J. 2012;33:2403-18.

17. Vahanian A, Alfieri O, Andreotti F, Antunes MJ, Barón-Esquivias G Baumgartner H, et al. ESC Committee for Practice Guidelines (CPG), Join Task Force on the Management of Valvular Heart Disease of the European Society of Cardiology (ESC), European Association for Cardio-Thoracic Surgery (EACTS). Guidelines on the management of valvular heart disease (version 2012): the Joint Task Force on the Management of Valvular Heart Disease of the European Society of Cardiology (ESC) and the European Association for Cardio-Thoracic Surgery (EACTS). Eur J Cardiothorac Surg. 2012;42:S1-44.

18. Repossini A, Kotelnikov I, Bouchikhi R, Torre T, Passaretti B, Parodi O, et al Single-suture line placement of a pericardial stentless valve. J Thorac Cardiovasc Surg. 2005;130:1265-9.

19. Pibarot P, Dumesnil JG. Prosthesis-patient mismatch: definition, clinical impact, and prevention. Heart. 2006;92:1022-9.

20. Austin PC. An Introduction to Propensity Score Methods for Reducing the Ef fects of Confounding in Observational Studies. Multivariate Behav Res. 2011; 46:399-424.

21. McMurry TL, Hu Y, Blackstone EH, Kozower BD. Propensity scores: methods, considerations, and applications in the Journal of Thoracic and Cardiovascular Surgery. J Thorac Cardiovasc Surg. 2015;150:14-9.

22. Normand ST, Landrum MB, Guadagnoli E, Ayanian JZ, Ryan TJ, Cleary PD et al. Validating recommendations for coronary angiography following acute myocardial infarction in the elderly: a matched analysis using propensity scores. J Clin Epidemiol. 2001;54:387-98.

23. Xu S, Ross C, Raebel MA, Shetterly S, Blanchette C, Smith D. Use of stabilized inverse propensity scores as weights to directly estimate relative risk and its confidence intervals. Value Health. 2010;13:273-7.

24. Santarpino G, Pfeiffer S, Jessl J, Dell'Aquila AM, Pollari F, Pauschinger M, et al Sutureless replacement versus transcatheter valve implantation in aortic valve stenosis: a propensity-matched analysis of 2 strategies in high-risk patients. $J$ Thorac Cardiovasc Surg. 2014;147:561-7.

25. Kalavrouziotis D, Rodés-Cabau J, Bagur R, Doyle D, De Larochellière R Pibarot $\mathrm{P}$, et al. Transcatheter aortic valve implantation in patients with severe aortic stenosis and small aortic annulus. J Am Coll Cardiol. 2011;58: 1016-24.

26. Finkelstein A, Schwartz AL, Uretzky G, Banai S, Keren G, Kramer A, et al. Hemodynamic performance and outcome of percutaneous versus surgical stentless bioprostheses for aortic stenosis with anticipated patient-prosthesis mismatch. $J$ Thorac Cardiovasc Surg. 2014;147:1892-9.

27. G1 Cohen, Zagorski B, Christakis GT, Joyner CD, Vincent J, Sever J, et al. Are stentless valves hemodynamically superior to stented valves? Long-term followup of a randomized trial comparing Carpentier-Edwards pericardial valve with the Toronto Stentless Porcine Valve. J Thorac Cardiovasc Surg. 2010;139: 848-59.

28. Narang S, Satsangi DK, Banerjee A, Geelani MA. Stentless valves versus stented bioprostheses at the aortic position: midterm results. J Thorac Cardiovasc Surg. 2008;136:943-7.

29. Lopez S, Mathieu P, Pibarot P, Mohammadi S, Dagenais F, Voisine P, et al. Does the use of stentless aortic valves in a subcoronary position preven patient-prosthesis mismatch for small aortic annulus? J Card Surg. 2008; 23:331-5. 
30. Wollersheim LW, Li WW, Bouma BJ, Repossini A, van de Meulen J, de Mol BA. Aortic valve replacement with the stentless Freedom SOLO bioprosthesis: a systematic review. Ann Thorac Surg. 2015;100:1496-504.

31. Dvir D, Webb JG, Piazza N, Blanke P, Barbanti M, Bleiziffer S, et al. Multicenter evaluation of transcatheter aortic valve replacement using either SAPIEN XT or CoreValve: Degree of device oversizing by computed-tomography and clinical outcomes. Catheter Cardiovasc Interv. 2015;86:508-15.

32. Kasel AM, Cassese S, Bleiziffer S, Amaki M, Hahn RT, Kastrati A, et al. Standardized imaging for aortic annular sizing: implications for transcatheter valve selection. JACC Cardiovasc Imaging. 2013;6:249-62.

33. Détaint D, Lepage L, Himbert D, Brochet E, Messika-Zeitoun D, Iung B, et al. Determinants of significant paravalvular regurgitation after transcatheter aortic valve implantation: impact of device and annulus discongruence. J Am Coll Cardiol Intverv. 2009;2:821-7.

Key Words: stentless aortic prosthesis, transcatheter aortic valves, small aortic annulus, haemodynamics, intermediate risk

\section{Discussion}

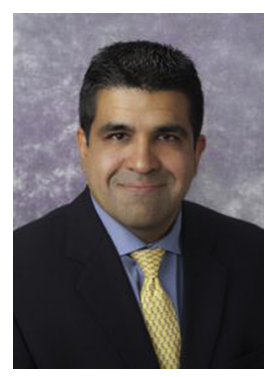

Dr J. Bhama (Pittsburgh, Pa). Thank you for your presentation describing the results of a multicenter propensity-matched analysis of surgical aortic valve replacement with the Freedom SOLO stentless bioprosthesis versus TAVR for intermediate-risk patients with small aortic annulus dimension. I have 3 questions.

First, the study spanned 4 years, from 2010 to 2014. Did you observe any temporal trends in outcomes in the TAVR group related to a learning curve? Second, the study involved 5 centers in 3 countries across Europe. Was there heterogeneity with regards to outcomes across the centers, or did you observe the same overall trend in outcomes across all the centers? Finally, it is well accepted that standard cardiac surgical risk scores, such as the STS score, do not account for all aspects of surgical risk, such as frailty? Do you think controlling for this may have altered the results of the study?

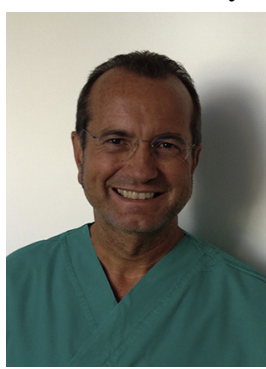

Dr Repossini. (Brescia, Italy) Thank you for your questions. For sure, when you study something for a long time, you could have some learning curve. In this particular field, the surgical learning curve concerning the stentless valve was not taken into consideration because all the centers have been implanting that kind of valve since at least 10 years.

Concerning TAVI, we just have been proctored in the first cases by, let's say, expert proctors, so I do not think that the results are influenced by this bias.

About your observation for the STS evaluation, you are probably right. Every surgeon knows very well that concerns about frailty or obesity or other parameters not included in the STS score are really debatable in patients' selection, but this is real-world, multicenter clinical study, and it is very difficult to use same assessment tools in different centers.

And the third one was?

Dr Bhama. Just regarding whether had you controlled for frailty do you think the result would have been the same?

Dr Repossini. We always include frailty and obesity in patients' evaluation without objectivating with scores. Anyhow, I don't think we would have had a significant variation. 


\section{Standardized differences before matching}

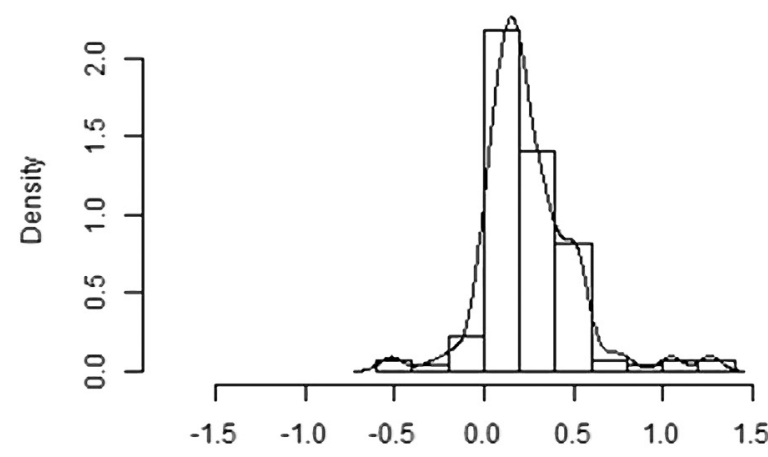

Std. difference

\section{Standardized differences after matching}

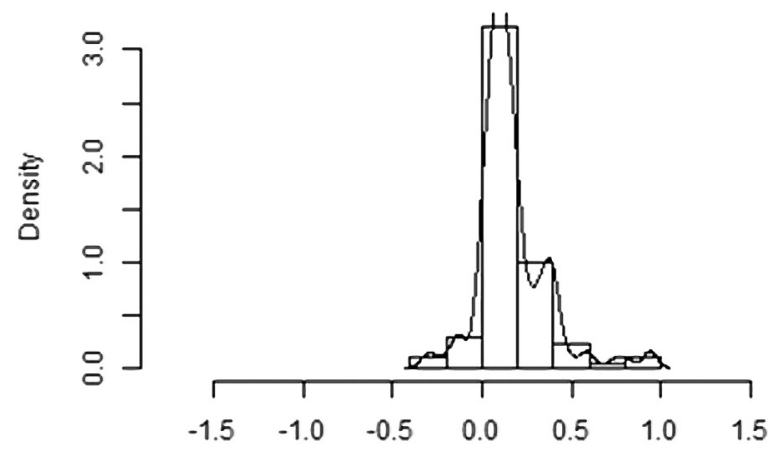

Std. difference

FIGURE E1. Standardized differences distribution before and after matching.

TABLE E1. Sensitivity analysis for hard endpoints (mortality)

Parameter estimates

\begin{tabular}{|c|c|c|c|c|c|c|c|c|c|c|}
\hline \multirow[b]{2}{*}{ Parameter } & \multirow[b]{2}{*}{ B } & \multirow[b]{2}{*}{ Std. error } & \multicolumn{2}{|c|}{ Interval } & \multicolumn{3}{|c|}{ Hypothesis test } & \multirow[b]{2}{*}{$\operatorname{Exp}(B)$} & \multicolumn{2}{|c|}{ Interval for $\operatorname{Exp}(B)$} \\
\hline & & & Lower & Upper & Wald $\chi^{2}$ & df & Sig. & & Lower & Upper \\
\hline $\begin{array}{l}\text { (Intercept) } \\
\text { nat }\end{array}$ & -3.840 & .3881 & -4.600 & -3.079 & 97.858 & 1 & 0.000 & .022 & .010 & .046 \\
\hline [group $=1.00]$ & 1.338 & .5309 & .298 & 2.379 & 6.356 & 1 & .012 & 3.813 & 1.347 & 10.792 \\
\hline (Scale) & 1 & & & & & & & & & \\
\hline
\end{tabular}


TABLE E2. Unmatched patient characteristics

\begin{tabular}{|c|c|c|c|}
\hline Characteristes & $\frac{\text { FS group, } \mathbf{n}=278}{n(\%)}$ & $\frac{\text { TAVR group, } \mathbf{n}=\mathbf{2 3 3}}{\mathrm{n}(\%)}$ & $P$ value \\
\hline Age, $y$, mean $\pm S D$ & $74.4 \pm 9.6$ & $80.3 \pm 8.2$ & .002 \\
\hline Female sex & $119(42.8)$ & $122(52.3)$ & .033 \\
\hline NYHA III-IV & $118(42.4)$ & $192(82.4)$ & $<.001$ \\
\hline $\mathrm{BMI}, \mathrm{kg} / \mathrm{m}^{2}$, mean $\pm \mathrm{SD}$ & $26.9 \pm 5.6$ & $26.7 \pm 2.9$ & .745 \\
\hline BMI $>30 \mathrm{~kg} / \mathrm{m}^{2}$ & $57(20.5)$ & $49(21)$ & .913 \\
\hline $\mathrm{BSA}, \mathrm{m}^{2}$ & $1.59 \pm 0.15$ & $1.58 \pm 0.21$ & .838 \\
\hline Diabetes & $73(26.2)$ & $70(30)$ & .374 \\
\hline Dyslipidemia & $90(32.3)$ & $99(42.4)$ & .021 \\
\hline Hypertension & $179(64.3)$ & $190(81.5)$ & $<.001$ \\
\hline Severe COPD $\left(\mathrm{FEV}_{1}<50 \%\right)$ & $39(14)$ & $61(26.1)$ & .001 \\
\hline PAD & $43(15.4)$ & $74(31.7)$ & $<.001$ \\
\hline Recent MI & $24(8.6)$ & $19(8.1)$ & .874 \\
\hline Previous CVA & $20(7.1)$ & $35(15)$ & .006 \\
\hline $\mathrm{CRF}(\mathrm{GFR}<30 \mathrm{~mL} / \mathrm{min})$ & $34(12.2)$ & $123(52.7)$ & $<.001$ \\
\hline $\mathrm{LVEF}, \%$, mean $\pm \mathrm{SD}$ & $54 \pm 13$ & $53.8 \pm 11.1$ & .325 \\
\hline LVEF $30 \%-50 \%$ & $79(28.4)$ & 97 (41.6) & .002 \\
\hline LVEF $<30 \%$ & $10(3.5)$ & $22(9.4)$ & .009 \\
\hline PAPs $>30 \mathrm{~mm} \mathrm{Hg}$ & $63(22.6)$ & $131(56.2)$ & $<.001$ \\
\hline Permanent PM & $7(2.5)$ & $11(4.7)$ & .229 \\
\hline Frailty (5-m walk test time $>7 \mathrm{~s}$ ) & $63(22.6)$ & $66(28.3)$ & .153 \\
\hline Reoperation & $2(0.7)$ & $41(17.6)$ & $<.001$ \\
\hline Endocarditis & $12(4.3)$ & $3(1.2)$ & .100 \\
\hline STS Score & $6.1 \pm 4.2$ & $10.1 \pm 5.9$ & .005 \\
\hline
\end{tabular}

FS, Freedom SOLO; TAVR, transcatheter aortic valve replacement; $N Y H A$, New York Heart Association; $B M I$, body mass index; $S D$, standard deviation; $B S A$, body surface area; $C O P D$, chronic obstructive pulmonary disease; $F E V_{l}$, forced expiratory volume first second; $P A D$, peripheral artery disease; $M I$, myocardial infarction; $C V A$, cerebrovascular accident; $C R F$, chronic renal failure; $G F R$, glomerular filtration rate; $L V E F$, left ventricular ejection fraction; PAPs, systolic pulmonary artery pressure; $P M$, pacemaker; $S T S$, Society of Thoracic Surgeons.

TABLE E3. Unmatched patient postoperative outcomes

\begin{tabular}{|c|c|c|c|}
\hline & FS group, $n=278$ & TAVR group, $n=233$ & \\
\hline & n $(\%)$ & n $(\%)$ & $P$ value \\
\hline \multicolumn{4}{|l|}{ Preoperative ECHO } \\
\hline Peak transvalvular gradient, mm Hg & $77.5 \pm 32.7$ & $78.9 \pm 26.8$ & .134 \\
\hline Mean transvalvular gradient, $\mathrm{mm} \mathrm{Hg}$ & $45.8 \pm 20.2$ & $46.1 \pm 18.3$ & .427 \\
\hline $\mathrm{EOA}, \mathrm{cm}^{2}$ & $0.69 \pm 0.3$ & $0.69 \pm 0.2$ & .117 \\
\hline EOAI, $\mathrm{cm}^{2} / \mathrm{m}^{2}$ & $0.33 \pm 0.13$ & $0.34 \pm 0.24$ & .758 \\
\hline Annular diameter, $\mathrm{mm}$ & $22.2 \pm 1.3$ & $21.8 \pm 1.4$ & .534 \\
\hline Emergency surgery & $2(0.7)$ & $6(2.5)$ & .648 \\
\hline MAV $>48 \mathrm{~h}$ & $5(1.7)$ & $3(1.2)$ & .738 \\
\hline $\mathrm{ICU}$ stay, $\mathrm{d}$, mean $\pm \mathrm{SD}$ & $1.8 \pm 1.6$ & $3.6 \pm 2.2$ & .008 \\
\hline Mean valve diameter & $22.3 \pm 0.8$ & $22.1 \pm 0.9$ & .596 \\
\hline $\mathrm{CPB}$ time, min, mean $\pm \mathrm{SD}$ & $73 \pm 18$ & - & \\
\hline Aortic crossclamp time, min, mean $\pm \mathrm{SD}$ & $59 \pm 19$ & - & \\
\hline Transapical TAVR & - & $59(25.32)$ & \\
\hline Other TAVR approaches & - & $10(4.2)$ & \\
\hline \multicolumn{4}{|l|}{ Postoperative TTE } \\
\hline Peak transvalvular gradient, $\mathrm{mm} \mathrm{Hg}$ & $19.1 \pm 8.6$ & $19.2 \pm 9.1$ & .572 \\
\hline Mean transvalvular gradient, $\mathrm{mm} \mathrm{Hg}$ & $9.8 \pm 7.5$ & $10.1 \pm 6.5$ & .884 \\
\hline $\mathrm{EOA}, \mathrm{cm}^{2}$ & $1.91 \pm 0.52$ & $1.89 \pm 0.3$ & .651 \\
\hline EOAI, $\mathrm{cm}^{2} / \mathrm{m}^{2}$ & $1.12 \pm 0.22$ & $1.02 \pm 0.31$ & .738 \\
\hline Severe PPM & $0(0.0)$ & $0(0.0)$ & 1.000 \\
\hline $\mathrm{PVL} \geq$ grade II & $3(1.0)$ & $9(3.8)$ & .486 \\
\hline
\end{tabular}

FS, Freedom SOLO; TAVR, transcatheter aortic valve replacement; TTE, transthoracic echocardiography; EOA, effective orifice area; EOAI, EOA index; MAV, mechanicalassisted ventilation; $I C U$, intensive care unit; $S D$, standard deviation; $C P B$, cardiopulmonary bypass; $P P M$, prostheses-patient mismatch; $P V L$, perivalvular leak. 
TABLE E4. Unmatched patient outcomes

\begin{tabular}{|c|c|c|c|}
\hline \multicolumn{4}{|c|}{ Unmatched } \\
\hline & $\underline{\text { FS group, }, \mathbf{n}=\mathbf{2 7 8}}$ & TAVR group, $\mathbf{n}=\mathbf{2 3 3}$ & \\
\hline & n $(\%)$ & n $(\%)$ & $P$ value \\
\hline 30-d mortality & $6(2.1)$ & $19(8.1)$ & .002 \\
\hline Valve-related death & $0(0.0)$ & $5(2.1)$ & .019 \\
\hline Cardiac death & $4(1.4)$ & $14(6.0)$ & .012 \\
\hline Annular rupture & $0(0.0)$ & $1(0.4)$ & .456 \\
\hline CVA & $7(2.5)$ & $11(4.7)$ & .229 \\
\hline Perioperative AMI & $1(0.3)$ & $6(2.5)$ & .051 \\
\hline Postoperative PBRC & $84(30.2)$ & $77(33.0)$ & .505 \\
\hline Acute renal failure & $11(3.9)$ & $18(7.7)$ & .119 \\
\hline CVVH & $3(1.0)$ & $10(4.2)$ & .025 \\
\hline AVB requiring PM implantation & $3(1.0)$ & $30(12.8)$ & $<.001$ \\
\hline ARDS & $4(1.4)$ & $5(2.1)$ & .738 \\
\hline Peripheral vascular complications & $0(0.0)$ & $27(11.5)$ & $<.001$ \\
\hline Sepsis & $7(2.5)$ & $14(6.0)$ & .071 \\
\hline
\end{tabular}

